\title{
Delirium in Patients with Covid-19
}

\section{Madhusudhan $\mathbf{S}^{1 *}$, Shreekara ${ }^{2}$, Chandrashekar $\mathrm{H}^{3}$, Pranjal Sharma ${ }^{2}$, Amit $^{2}$, Jeevan ${ }^{2}$ and Anjana $R^{4}$}

${ }^{1}$ Associate Professor, Department of Psychiatry, Victoria Hospital BMCRI,

Bangalore, India

${ }^{2}$ Psychiatry Residents, Department of Psychiatry, Victoria Hospital BMCRI,

Bangalore, India

${ }^{3}$ Professor and HOD, Department of Psychiatry, Victoria Hospital BMCRI,

Bangalore, India

${ }^{4}$ Psychiatry Senior Resident, Department of Psychiatry, Victoria Hospital BMCRI,

Bangalore, India

*Corresponding Author: Madhusudhan S, Associate Professor, Department of

Psychiatry, Victoria Hospital BMCRI, Bangalore, India.
Received: December 16, 2021

Published: January 05, 2022

(C) All rights are reserved by Madhusudhan

S., et al.

\section{Abstract}

Background: Victoria hospital a specialized COVID center in Bangalore saw more than 10,000 patients with COVID-19 infection who have been admitted to our hospital. Most of the patients that were taken up for the study were moderate to severely ill and at a risk of developing acute delirium, Neurotropic properties of SARS-CoV-2 and its neurological expressions have been established, this study hence was designed to find the prevalence and risk factors for developing acute delirium in patients admitted with COVID-19 infection.

Method: The study includes 10,200 covid infected patient admitted to Victoria hospital, of which about 550 cases were found to have neuropsychiatric symptoms.

Patients who were on life support, prisoners, patients were with pre-existing Psychiatric illness, neurodegenerative disorders, congenital or acquired brain damage, hepatic coma, drug dependence (Except ADS and NDS), suicide attempt were excluded. Patients with blind deafness were excluded.

The study was designed to determine the prevalence of delirium and to ascertain if there are any associated risk factors for delirium.

Findings: From June 2020 to June 2021, about 10,200 patients with COVID-19 were admitted to Victoria Hospital. Bangalore. Out of which 550 patients having neuropsychiatric symptoms were taken into the study.

The mean age of patients was 60 years. The males account for $68 \%$ and females $32 \%$, all were from urban back ground. About $80 \%$ of them had medical history, only $10 \%$ had past history of alcohol dependence and BPAD.

About $40 \%$ of cases were treated in ICU, and $32 \%$ of them were treated on Ventilators.

Lab Investigations revealed inflammatory markers to be raised in almost all (C- reactive protein 100\%, D-dimmer 64\% and Serum ferritin 69\%). About 88\% are Positive SARS-CoV-2 RT-PCR in nasopharyngeal swabs. In HRCT chest 98\% are suggestive of SARSCoV-2 infection. Treatment given was Steroids (Inj Dexamethasone IV) in 100\% cases, antiviral Remdesivir in 85\%, Ivermectin or Hydroxychloroquine in $80 \%$, IV antibiotics (Cephalosporin) in 100\%, Tocilizumab/Antibody/Plasma therapy in 0\%. For Symptom-

Citation: Madhusudhan S., et al. "Delirium in Patients with Covid-19". Acta Scientific Neurology 5.2 (2022): 03-10. 
atic delirium treatment Inj Haloperidol Iv $1.5 \mathrm{mg}$ to $5 \mathrm{mg}$ thrice per day to once daily in 98\% case, some received Quetiapine $12.5 \mathrm{mg}$ to $100 \mathrm{mg}$ /day in $5 \%$ or Tab Olanzapine $2.5 \mathrm{mg}$ to $10 \mathrm{mg}$ per day in $9 \%$ cases. Delirium Mortality rate was $45 \%$ and recovery rate was $55 \%$.

Conclusions: Severe SARS-CoV2 infection may be associated with COVID-19 delirium and high mortality, (more than 50\%) in covid delirium patients. Hypoxia could be the main reason for delirium in Covid 19. Elevated inflammatory markers were associated with Delirium in covid 19 patients.

Keywords: Delirium; SARS-CoV-2; Inflammatory Markers Mortality

\section{Introduction}

Patients with symptoms similar to severe acute respiratory syndrome coronavirus-2 (SARS-CoV-2), or [COVID-19], mainly report respiratory symptoms which are similar to viral structure and infectious pathways. Early literature about the epidemic of SARS$\mathrm{CoV}-2$ is suggestive that it attacks the central nervous system and accountable for neurological signs which mimic coronavirus.

SARS-CoV and $\beta$-coronaviruses, have a tendency to be neuro invasive. A cellular receptor angiotensin-converting enzyme 2 is used by the SARS-CoV cells by using (ACE2), which may be expressed in the central nervous system, ciliated upper respiratory cells and type II pneumocytes. A series of autopsies by von Weyhern., et al. described involvement of central systema nervosum with brainstem neuronal cell damage, lymphocytic panencephalitis, meningitis and diffuse petechial hemorrhages.

Presence of SARS-CoV particles was revealed within the brain of patients with SARS.

Mao., et al. found that in patients hospitalized in Wuhan, China that retrospectively neurological manifestations of SARS-CoV-2 infection was confirmed in 78 of 214 (36.4\%) diagnosis of COVID-19. They reported that 53 (24.8\%) of the patients suffered from symptoms of central systema nervosum, which included dizziness, headache, and impaired consciousness. (84\%) of Patients admitted to hospitals for acute respiratory distress syndrome (ARDS) and COVID-19 have found to develop neurological features, mainly delirium.

Delirium reported from within the ICU includes fluctuations in attention and cognition developing during a short period that cannot be explained by pre-existing neurocognitive disorders, both neurotropism and its neurological manifestations have now been confirmed to be of SARS-CoV-2.
Delirium could be a clinical syndrome which is difficult to define. The terms include 'acute confusional state', or "acute encephalopathy'. consistent with DSM-5 criteria. Delirium is distinguished by disturbance of consciousness, inattention, and reduced awareness, which is seen occurring in $20 \%$ of acute inpatients. They also have reported experiencing hallucinations or delusions.

Delirium can be described with the terms like hyperactive, hypoactive, or mixed labels depending on the extent of arousal. Of all these types Hyperactive delirium is the easily recognized type, marked by agitation and vigilance, while the other type hypoactive form is denoted by lethargy, and a substantially decreased level of motor activity.

ICD-10 criteria for delirium [14]

- Clouding of consciousness or brain fog.

- Cognitive disturbances.

- A minimum of one among the subsequent psychomotor disturbances:

- $\quad$ Sleep Disturbance or the disturbance in sleep-wake cycle.

- Onset and fluctuations of the symptoms over the course of the day are rapid.

- $\quad$ Objectivity in evidence from patient's history, physical examination and neurological examination or laboratory investigations of an underlying cerebral or systemic disease (other than psychoactive substance-related) which will provide a proof for the clinical manifestations in A-D.

\section{Delirium and COVID-19}

World Health Organization, has also thrust the fact that "altered consciousness/confusion" could be a presenting symptom of COVID-19, even before fever and cough [16]. 
In older adults, it is observed that a virus infection like COVID-19, with fever, and hypoxemia may instigate delirium. Comorbidities also may facilitate the onset of an acute state of confusion. Higher levels of serum pro-interleukins and S100B was observed during delirium in elderly patients. Critically ill and those requiring ICU-level care, are prone to develop delirium.

11 to $12 \%$ prevalence of delirium has been reported in COVID-19 patients with high risk of delirium with systemic inflammation, neuroinflammation, organ failure, thrombosis, with the effects of deep sedative strategies, prolonged mechanical ventilation, and social isolation from families have been found to affect delirium.

COVID-19 delirium could also be a resultant of acute respiratory distress syndrome, stress caused by diffuse damage of the alveola, pulmonary emboli, cerebral apoplexy, decreased blood flow, chronic renal failure, and other metabolic dysfunctions.

Hyercytokinemia, endothelial transfer and penetration of inflammatory cytokines via the damaged Blood Brain Barrier are likely to induce encephalopathy. one among the severe manifestation is acute hemorrhagic necrotizing encephalopathy (AHNE) caused by SARS-CoV-2 infection and possibly in link with cytokine storm.

In delirium the important steps in management are to target all glaring causes, providing supportive care, preventing complications, and treating behavioral symptoms. Primarily management of the patients with delirium should begin with ascertaining the standard assessment of airway, breathing, and circulation. Hyperactive delirium present particular challenges within the context of the COVID crisis. Sedation precipitates and worsens hypoactive delirium. the use of neuroleptic drugs has to be the drug of choice if the person is suffering from severe hallucinations/delusions, as there is a risk of harm to themselves or others during the course of delirium precipitating from COVID-19.

Preferential treatment should be to begin with a low-dose lorazepam or haloperidol and to increase the dose and frequency slowly as required, it is also essential to be aware of benzodiazepines causing respiratory distress. In cases which are diagnosed to be severe, both antipsychotics and lorazepam can be administered.

\section{Methodology}

Study design

A cross sectional study in Victoria hospital Bangalore, Karnataka state Government Hospital exclusively for Covid 19 infection treatment.

\section{Duration}

All the patients admitted Between June 2020 and June 15, 2021 were taken up for the study.

\section{Aims of the Study}

To find

- $\quad$ The prevalence rate of Delirium in patients with COVID-19.

- Hypoxia in brain as a risk factor for development of delirium.

- $\quad$ Elevated Inflammatory markers, are to be ascertained as a risk factor for developing delirium.

- High Mortality rate to be established in Covid delirium.

Inclusion and exclusion criteria

Inclusion

- $\quad$ Age - Above 18 yrs. Both Gender

- With Covid RT PCR Positive for SARS-CoV-2.

\section{Exclusion}

- $\quad$ Patients who did not survive for more than 24 hours of admission or had life-support measures withdrawn within 24 hours of admission into ICU.

- Patients with pre-existing mental illness like schizophrenia, psychosis, or major depression,

- Patients with neurodegenerative disorders like Dementia or Parkinson's disease.

- $\quad$ Congenital or acquired brain damage like stroke in the 2 weeks before admission, hemorrhage, seizures, brain injury due to anoxia, overdose of drugs, suicide attempts and those with blind deafness.

\section{Ethical committee clearance}

The ethics committee of the Bangalore Medical college and research Institute consented to the study. Due to Covid infection, not all patients were able to give their oral consent, but their relatives gave consent on their behalf which was considered as the patients consent itself however after the critical stage had passed consent was taken by the patient or their relative in case of death.

- The demographic details including medical history were taken. Clinical examination was performed daily. The assessment scale was applied twice daily.

- Peripheral Oxygen saturation measured by Pulse Oximeter,

- Quantitative RTPCR tests for COVID-19 were performed by nasopharyngeal swabs for all patients. 
- $\quad$ Cerebro Spinal Fluid analysis, EEG, and brain MRI were also studied for selected critically ill patients.

- $\quad$ Lab investigations - Complete Blood counts, Liver Function tests, Renal Function tests. Serum electrolytes, Blood gas analysis.

- ICD 10 criteria for Delirium were applied for diagnosis, along with Confusion Assessment Method Scale (CAM). Which was used to classify delirium into hypoactive or hyperactive delirium correlating with the clinical presentation [21].

Data was obtained both from patient as well as case file of the patient. All the readings were taken up for statistical analysis.

\section{Results and Analysis}

Delirium

550 patients Out of 10,200 were presented with neuropsychiatric symptoms were taken up for the study. Out of these 550 patients, 106 were diagnosed with Delirium after excluding history of head injury, neurodegenerative disorders, psychiatric illness and drug dependence (Except ADS and NDS).

\begin{tabular}{|l|c|c|}
\hline Total patients with delirium & N & Percentage \\
\hline Male patients & $\mathrm{N}=72$ & $68 \%$ \\
\hline Female patients & $\mathrm{N}=34$ & $32 \%$ \\
\hline & 106 & $100 \%$ \\
\hline
\end{tabular}

Table 1: Socio demographic details.

- $\quad$ Age $=$ The mean age of patients was 60 years.

- $\quad$ Sex $=$ The males accounts for 68 percent and female were 32 percent.

- $\quad$ Locality= Urban back ground - Bangalore.

\begin{tabular}{|l|c|c|}
\hline Past Medical history & Total N = 106 & Percentage \\
\hline $\begin{array}{l}\text { No. of pts with past medical } \\
\text { history }\end{array}$ & 85 & 80 \\
\hline $\begin{array}{l}\text { No. of pts with alcohol } \\
\text { dependence syndrome }\end{array}$ & 11 & 10 \\
\hline Nil & 10 & 10 \\
\hline & 106 & 100 \\
\hline
\end{tabular}

Table 2: Past Medical history.

- About 80 percent of them had medical history, only 10 percent had past history of Alcohol dependence.

\begin{tabular}{|l|c|c|}
\hline Wards / ICU & N & Percentage \\
\hline No. of pts treated in ICU & 42 & 40 \\
\hline No. of pts treated in ward & 64 & 60 \\
\hline & 106 & 100 \\
\hline
\end{tabular}

Table 3: ICU beds and Ventilators.

- About $40 \%$ of cases are from ICU, and $32 \%$ of them, are treated on Invasive mechanical ventilation (Ventilators).

- Remaining $60 \%$ of Delirium cases were treated in wards with high flow oxygen, Non-Rebreather Oxygen face mask

- Inflammatory marker raised in patients as below

\begin{tabular}{|l|c|c|}
\hline Inflammatory markers elevated & $\mathbf{N}$ & Percentage \\
\hline CRP & 106 & 100 \\
\hline D-DIMER & 68 & 64 \\
\hline Seum. Ferritin & 74 & 69 \\
\hline LDH & 83 & 78 \\
\hline
\end{tabular}

Table 4: Lab Investigation

- C- reactive protein $100 \%$,

- D-dimmer $64 \%$ and

- Serum ferritin 69\%

- $\quad$ SARS-CoV-2 RT-PCR in nasopharyngeal swabs is $88 \%$ were Positive.

Imaging by HRCT chest

98\% were suggestive of SARS-CoV-2 infection.

\begin{tabular}{|l|c|c|}
\hline Mode of Oxygen therapy & N & Percentage \\
\hline Pts on Invasive mechanical ventilation & 34 & 32 \\
\hline Pts on High Flow Nasal Oxygen & 42 & 39 \\
\hline Pts on Oxygen NRBM & 21 & 19 \\
\hline Pts on Oxygen FM & 9 & 8 \\
\hline & 106 & 100 \\
\hline
\end{tabular}

Table 5: Oxygen Therapy.

No. of Cases treated in ICU were 39.62\% ( $\mathrm{N}=42)$

- Invasive mechanical ventilation (ICU Pts) were $32.07 \%$ (N = 34)

- $\quad$ Remaining ( $\mathrm{N}=8)$ in ICU were on High Flow Nasal Oxygen (HFNO). 
No. of Cases treated in the ward were $60.37 \%(\mathrm{~N}=64)$.

- Non-Invasive mechanical ventilation patients in the ward were

- $\quad$ No. of pts who were on High Flow Nasal Oxygen $(\mathrm{HFNO})=(8$ pts in ICU, 34 pts in ward $(8+34)$ was $39.62 \%(\mathrm{~N}=42)$

- $\quad$ No. of pts who were on Non-Rebreather Mask (NRBM) 1416ltr of $\mathrm{O}_{2} / \mathrm{min}$ is $19.81 \%(\mathrm{~N}=21)$

- $\quad$ No. of pts who were on Oxygen Face mask - (FM) (8-10 ltr of $\mathrm{O}_{2} / \mathrm{min}$.) $(8.49 \%)(\mathrm{N}=9)$.

\begin{tabular}{|l|c|c|}
\hline Medical Treatment given & N & Percentage \\
\hline Steroids & 106 & 100 \\
\hline Remdesivir & 91 & 85 \\
\hline Ivermectin & 85 & 80 \\
\hline IV antibiotics & 106 & 100 \\
\hline
\end{tabular}

Table 6: Treatment.

- $\quad$ Steroids (Dexamethasone) in $100 \%$,

- Antiviral

- Remdesivir in 85\%,

- Ivermectin or Hydroxychloroquine in $80 \%$,

- Iv antibiotics (Cephalosporin) in $100 \%$,

- $\quad$ Tocilizumab/Antibody/Plasma therapy in 0\%.

\begin{tabular}{|l|c|c|}
\hline Psychiatry treatment given & N & Percentage \\
\hline Inj. Haloperidol 1.5 mg to 5 mg & 104 & 98 \\
\hline Inj. Lorazepam 1 mg to 4 mg & 44 & 41.5 \\
\hline Tab. Clonazepam & 4 & 3.8 \\
\hline Tab. Quetiapine & 6 & 5 \\
\hline Tab. Olanzapine & 10 & 9 \\
\hline
\end{tabular}

Table 7: Symptomatic delirium treatment.

- $\quad$ Inj Haloperidol IV $1.5 \mathrm{mg}$ to $5 \mathrm{mg}$ Thrice per day to once a day dose in $98 \%$ case,

- $\quad$ Inj Lorazepam $1 \mathrm{mg}$ to $2 \mathrm{mg}$ IV BID to TID per day in $41.5 \%$

- Tab Clonazepam $0.25 \mathrm{mg}$ to $0.5 \mathrm{mg}$ night dose $3.8 \%$

- $\quad$ Some patients received Quetiapine $12.5 \mathrm{mg}$ to $100 \mathrm{mg} /$ day in $5 \%$ or Tab Olanzapine $2.5 \mathrm{mg}$ to $10 \mathrm{mg}$ per day in $9 \%$ cases.

- $\quad 55 \%$ recovered and $45 \%$ suffered death.

\begin{tabular}{|l|c|c|}
\hline Outcome of delirium & N & Percentage \\
\hline Mortality & 58 & 55 \\
\hline Recovered & 48 & 45 \\
\hline & 106 & 100 \\
\hline
\end{tabular}

Table 8: Mortality due to Delirium.

\section{Discussion}

Many factors like prevalence of Delirium, Blood oxygen levels, raised Inflammatory markers, Social isolation and high mortality rate have been found to be confounding factors in patients with Delirium with COVID 19 in our studies.

Prevalence of Delirium in ICU or in covid wards

- The frequency of delirium in critically ill patients with COVID-19 is unknown, but in our study patients with COVID-19 are at a very high risk of delirium.

- In our study of the 520 cases of neurological symptoms out of 10,200 covid admitted cases, 106 had Delirium (100\%).

- $\quad$ Comparatively patients with acute respiratory failure without COVID-19 in [25]. Wuhan, China, reported that 40 (45\%) of 88 patients hospitalized with severe COVID-19 had symptoms of nervous system with 13 (15\%) having impaired consciousness [26].

- Helms., et al. [27] reported that among 140 patients, 118 (84\%) had delirium or abnormal neurological examination which highly correlated with time on ventilation, and the delirium prevalence of $11-12 \%$ was reported among the general population of hospitalized patients with COVID-19 $[22,32]$. Systemic inflammation, neuroinflammation, organ system failures, increased risk of thrombosis, effects of deep sedation, prolonged mechanical ventilation, and social isolation from families were common factors [23,24,27].

Blood oxygen levels

Neurological effects caused indirectly by factors such as low blood-oxygen levels, coagulopathy, exposure to inflammatory markers along with COVID infection was initially hypothesized to contribute directly to neurological symptoms [27-29].

Similarly, in our study low blood-oxygen levels in 98 cases out of 105 very low blood oxygen level leading to need for Oxygen because of acute respiratory distress syndrome, including low 
oxygen levels and oxidative stress due to damage in the alveola, pulmonary emboli and Apoplexy due to hypercoagulability and consumptive coagulopathy, as well as hypoperfusion, uremia, and other metabolic derailing due to multi-organ dysfunction $[35,36]$.

\section{Raised inflammatory markers:}

In our study, $100 \%$ raise in C-Reactive proteins in all cases of Delirium due to Covid 19.

C- reactive protein $100 \%$, the Inflammatory marker D-dimmer in $64 \%$ of cases and Serum ferritin in $69 \%$ of cases. Similarly other studies also show raised inflammatory markers, the development of secondary encephalopathy through hyperactivated immune response and cytokine storm, characterized by activation of $\mathrm{T}$ lymphocytes, macrophages, and endothelial cells and excessive release of pro-inflammatory cytokines such as interleukin, Creactive protein, D-dimer, procalcitonin, and ferritin [35-37].

\section{Social isolation}

- $\quad$ COVID-19 might be affected by social isolation also as a result of visitation rights of the family in most hospitals during the pandemic. Brenda., et al. in Lancet Reisp Med march 2021 found family visitations on less than $20 \%$ of eligible days, however, it was noticed that visitation had great benefits in that (virtual or in-person), the risk of delirium the following day significantly decreased (27\% lower) [30].

- Similarly in our study either ICU patients or Ward patients were denied a chance to meet their family members, but they had a chance to talk to their family members via mobile phones.

- Decreased anxiety, reduced length of stay, and increase in patients' sense of security, satisfaction, and quality of care increased with the presence of family in the ICU was noted [31].

\section{High mortality}

- In our study Mortality rate of $50 \%$ for covid patients with Delirium, has been noticed.

- $\quad$ Shih-Chieh Shao., et al. may 2021 reports in almost 1 out of 3 COVID-19 patients, a 3-fold overall mortality is associated amongst those who developed delirium [33].

- $\quad$ Raymond Pranata., et al. also reported that presence of delirium is associated with increased risk of mortality in older adults who were hospitalized with COVID-19 [34].
Limitations of our study

- $\quad$ Patients admitted to our hospital belonged to the same geographical area, Symptomatology and a minimal number of variants of corona virus was hence studied.

- No or Limited visitation rights to the patient's family members could be the cause of psychological distress among the patients.

- High risk of infection, deaths in health care workers, stress of wearing PPE kit for longer duration was extensively exhausting leading to limited information.

\section{Conclusion}

- $\quad$ Severe SARS-CoV2 infection is associated and go hand in hand with Delirium.

- $\quad$ High mortality, (more than 50\%) in delirium due to Covid 19 was noted.

- Hypoxia could be one of the reasons for delirium in Covid 19 in our study.

- Elevated inflammatory markers is associated with Delirium due to covid 19.

\section{Conflicts of Interest}

The authors declare there is no conflict of Interest in this study.

There was no funding received for this study.

The authors would like to thank the hospital authorities, patients and their relatives for participating in this study.

\section{Bibliography}

1. Glass WG., et al. "Mechanisms of host defense following severe acute respiratory syndrome-coronavirus (SARS-CoV) pulmonary infection of mice". Journal of Immunology 173.6 (2004): 4030-4039.

2. Zhu N., et al. "A novel coronavirus from patients with pneumonia in China, 2019". The New England Journal of Medicine 382.8 (2020): 727-733.

3. Roman GC., et al. "The neurology of COVID-19 revisited: a proposal from the Environmental Neurology Specialty Group of the World Federation of Neurology to implement international neurological registries". Journal of the Neurological Sciences 414 (2020): 116884. 
4. Lau KK., et al. "Possible central nervous system infection by SARS coronavirus”. Emerging Infectious Diseases 10.2 (2004): 342-344.

5. Arbour N., et al. "Neuroinvasion by human respiratory coronaviruses". Journal of Virology 74.19 (2000): 8913-8921.

6. Baig AM., et al. "Evidence of the COVID-19 virus targeting the CNS: tissue distribution, host-virus interaction, and proposed neurotropic mechanisms". ACS Chemical Neuroscience 11.7 (2020): 995-998.

7. Li YC., et al. "The Neuroinvasive potential of SARS-CoV2 may play a role in the respiratory failure of COVID-19 patients". Journal of Medical Virology 92.6 (2020): 552-555.

8. Von Weyhern CH., et al. "Early evidence of pronounced brain involvement in fatal COVID-19 outcomes". Lancet 395.10241 (2020): e109.

9. $\mathrm{Xu} \mathrm{J.,} \mathrm{et} \mathrm{al.} \mathrm{"Detection} \mathrm{of} \mathrm{severe} \mathrm{acute} \mathrm{respiratory} \mathrm{syndrome}$ coronavirus in the brain: potential role of the chemokine mig in pathogenesis". Clinical Infectious Diseases 41.8 (2005): 1089-1096.

10. Mao L., et al. "Neurologic manifestations of hospitalized patients with coronavirus disease 2019 in Wuhan, China". JAMA Neurology (2020).

11. Helms J., et al. "Neurologic features in severe SARS-CoV-2 infection". The New England Journal of Medicine (2020).

12. Slooter AJC., et al. "Updated nomenclature of delirium and acute encephalopathy: statement of ten societies". Intensive Care Medicine 46.5 (2020): 1020-1022.

13. American Psychiatric Association. Diagnostic and statistical manual of mental disorders, $5^{\text {th }}$ edn. American Psychiatric Association, Arlington, VA, USA (2013).

14. World Health Organization. The ICD-10 classification of mental and behavioral disorders: diagnostic criteria for research". WHO, Geneva (1993).

15. Inouye SK. "Delirium in older persons". The New England Journal of Medicine 354.11 (2006): 1157-1165.

16. Global COVID-19 Clinical Platform NOVEL CORONAVIRUS (COVID-19)-RAPID VERSION (2020).

17. Guan WJ., et al. "Comorbidity and its impact on 1590 patients with Covid-19 in China: a nationwide analysis". European Respiratory Journal (2020): 2000547.
18. McNeil JB., et al. "Plasma biomarkers of inflammation, coagulation, and brain injury as predictors of delirium duration in older hospitalized patients". PLoS ONE 14.12 (2020): e0226412.

19. Società Italiana di Psichiatria. "Raccomandazioni sulle attività e misure di contrasto e contenimento del virus SARSCOV-19 (2020).

20. Jenkinson J. "Delirium management advice for patients with confirmed or suspected COVID-19 in the acute trust setting (2020).

21. Chanques G., et al. "The CAM-ICU has now a French "official" version. The translation process of the 2014 updated Complete Training Manual of the Confusion Assessment Method for the Intensive Care Unit in French (CAM-ICU.fr)". Anaesthesia, Critical Care and Pain Medicine 36 (5 (2017): 297-300.

22. Ticinesi A., et al. "Delirium in COVID-19: epidemiology and clinical correlations in a large group of patients admitted to an academic hospital". Aging clinical and experimental research 32 (2020): 2159-2166.

23. Kotfis K., et al. "COVID-19: ICU delirium management during SARS-CoV-2 pandemic". Critical Care 24 (2020): 176.

24. Ellul MA., et al. "Neurological associations of COVID-19". Lancet Neurology 19 (2020): 767-783.

25. Girard TD., et al. "Haloperidol and ziprasidone for treatment of delirium in critical illness". The New England Journal of Medicine 379 (2018): 2506-2516.

26. Mao L., et al. "Neurological manifestations of hospitalized patients with COVID-19 in Wuhan, China: a retrospective case series study". medRxiv (2020).

27. Helms J., et al. "Delirium and encephalopathy in severe COVID-19: a cohort analysis of ICU patients". Critical Care 24 (2020): 491.

28. Solomon IH., et al. "Neuropathological features of Covid-19". The New England Journal of Medicine 383 (2020): 989-992.

29. Kanberg N., et al. "Neurochemical evidence of astrocytic and neuronal injury commonly found in COVID-19". Neurology 95 (2020): e1754-1759.

30. Brenda., et al. "Prevalence and risk factors for delirium in critically ill patients with COVID-19 (COVID-D): a multicenter cohort study". Lancet Respiratory Medicine 9 (2021): 239-250. 
31. Kleinpell R., et al. "Patient and family engagement in the ICU: report from the task force of the World Federation of Societies of Intensive and Critical Care Medicine". Journal of Critical Care 48 (2018): 251-256.

32. Garcez FB., et al. "Delirium and adverse outcomes in hospitalized patients with COVID-19". Journal of the American Geriatrics Society 68 (2020): 2440-2446.

33. Shih-Chieh Shao., et al. "Prevalence, incidence and mortality of delirium in patients with COVID-19: A systematic review and meta-analysis". Age Ageing (2020).

34. Raymond Pranata., et al. "Delirium and Mortality in Coronavirus Disease 2019 (COVID-19) - A Systematic Review and Metaanalysis". Archives of Gerontology and Geriatrics (2020).

35. Ahmad I and Rathore FA. "Neurological manifestations and complications of COVID-19: A literature review". Journal of Clinical Neuroscience: Official Journal of the Neurosurgical Society of Australasia 77 (2020): 8-12.

36. Beach SR., et al. "Delirium in COVID-19: A case series and exploration of potential mechanisms for central nervous system involvement". General Hospital Psychiatry 65 (2020): 47-53.

37. Huang I., et al. "C-reactive protein, procalcitonin, D-dimer, and ferritin in severe coronavirus disease-2019: a meta-analysis". Therapeutic Advances in Respiratory Disease (2020): 14.

\section{Assets from publication with us}

- Prompt Acknowledgement after receiving the article

- Thorough Double blinded peer review

- Rapid Publication

- Issue of Publication Certificate

- High visibility of your Published work

Website: www.actascientific.com/

Submit Article: www.actascientific.com/submission.php

Email us: editor@actascientific.com

Contact us: +919182824667 